\title{
THE
}

\section{The puzzle of problem-solving efficacy: understanding anxiety among urban children coping with asthma-related and life stress}

\author{
Kara Klein Murdock \\ Carolyn Greene \\ Sue K. Adams \\ University of Rhode Island, suekadams@uri.edu \\ William Hartmann
}

Sally Bittinger

See next page for additional authors

Follow this and additional works at: https://digitalcommons.uri.edu/hdf_facpubs

This is a pre-publication author manuscript of the final, published article.

Terms of Use

All rights reserved under copyright.

\section{Citation/Publisher Attribution}

Klein Murdock, K., Greene, C., Adams, S. K., Hartmann, W., Bittinger, S., \& Will, K. (2010). The puzzle of problem-solving efficacy: understanding anxiety among urban children coping with asthma-related and life stress. Anxiety Stress Coping, 23(4), 383-398. doi: 10.1080/10615800903118049

Available at: https://doi.org/10.1080/10615800903118049

This Article is brought to you for free and open access by the Human Development and Family Science at DigitalCommons@URI. It has been accepted for inclusion in Human Development and Family Science Faculty Publications by an authorized administrator of DigitalCommons@URI. For more information, please contact digitalcommons-group@uri.edu. 


\section{Authors}

Kara Klein Murdock, Carolyn Greene, Sue K. Adams, William Hartmann, Sally Bittinger, and Kelly Will 


\title{
The Puzzle of Problem-Solving Efficacy: Understanding Anxiety Among Urban Children Coping with Asthma-Related and Life Stress
}

\author{
Karla Klein Murdock, \\ Department of Psychology, Washington and Lee University \\ Carolyn Greene, \\ Department of Psychology, University of Massachusetts Boston \\ Sue K. Adams, \\ Department of Human Development and Family Studies, University of Rhode Island \\ William Hartmann, \\ Department of Psychology, Washington and Lee University
}

Sally Bittinger, and

Department of Psychology, Washington and Lee University

Kelly Will
Department of Psychology, Washington and Lee University

\begin{abstract}
Children with asthma living in urban environments are at risk for experiencing anxiety by virtue of both social context and health-related stressors. Although the use of active coping strategies is generally associated with more optimal psychosocial functioning, there is evidence that active coping is less helpful in response to uncontrollable or severe stress. Expectations that one can fix a problem that is uncontrollable or insurmountable may create distress. Problem-solving efficacy was examined as a moderator of the association between stress and anxiety among children residing in inner-city neighborhoods. It was hypothesized that children's perceptions of high problem-solving efficacy would exacerbate their vulnerability to stress. Forty-five parent-child dyads were recruited from urban community health centers. Most participants were members of ethnic minority groups. Hierarchical multiple regression analyses revealed main effects of asthmarelated stress and life stress on children's anxiety. However, these effects were moderated by problem-solving efficacy. Asthma-related stress and life stress were positively associated with anxiety only for children who had the highest levels of problem-solving efficacy. In other words, positive expectations about the ability to solve problems functioned as a liability for highly stressed children. Implications for psychosocial interventions with at-risk children are discussed.
\end{abstract}

\section{Keywords}

Asthma; problem-solving efficacy; stress; anxiety; child; ethnic minority

Correspondence concerning this article should be addressed to: Karla Klein Murdock, Department of Psychology, Washington and Lee University, Lexington, Virginia 24450. murdockk@ wlu.edu.

Carolyn Greene is now at the University of Connecticut Health Center Child Trauma Clinic. 
In the United States, asthma affects an estimated 6.8 million children under the age of 18 and is the third leading cause of hospitalization in children ages 15 and under (American Lung Association, 2008; Centers for Disease Control and Prevention, 2006). Children from minority backgrounds who live in low-income, inner-city environments experience disproportionately high levels of morbidity and mortality due to asthma (Castro, Schechtman, Halstead, \& Bloomberg, 2001).

\section{Asthma-Related Stress and Internalizing Problems}

Children with asthma face a range of symptoms such as shortness of breath, wheezing, and coughing, as well as impediments to optimal development such as sleep disruption, school absences, and activity restrictions. The burden of asthma management includes recognizing and communicating about their symptoms, using medications correctly, and adjusting their activities in response to symptom exacerbations.

Given these stressors, it is not surprising that children with asthma are at risk for experiencing higher levels of psychiatric (e.g., Vila, Nollet-Clemençon, de BlicMourenSiméoni, \& Scheinmann, 2000), behavioral (McQuaid, Kopel, \& Nassau, 2001), psychosocial (e.g., Taras and Potts-Detema, 2005) and school-related impairment (Koinis Mitchell \& Murdock, 2005; Moonie, Sterling, Figgs, \& Castro, 2006) than their physically healthy peers. Pediatric asthma has been associated with elevated risk for internalizing problems such as depressed mood and anxiety (Röder, Kroonenberg, \& Boekaerts, 2003), even when compared to other pediatric illnesses such as cancer or diabetes (Padur, Rapoff, Houston, \& Barnard, 1995). Onset of asthma by age 5 has been shown to significantly increase the likelihood of developing internalizing problems by age 14 (Alati et al., 2005). Youth with asthma have increased rates of anxiety disorders (Goodwin, Messineo, Bregante, Hoven, \& Kairam, 2005) and panic attacks (Goodwin, Pine, \& Hoven, 2003), and such comorbidity is associated with greater functional impairment (e.g., Katon, Richardson, Russo, Lozano, \& McCauley, 2006). Asthma-related functional impairment is a particular problem among children at risk by virtue of their socioeconomic, minority, and/or cumulative risk status (Josie, Greenley, \& Drotar, 2007; Newacheck \& Halfon, 2000), as it increases their burden of stress and creates an obstacle to their engagement in competencebuilding experiences.

The association between illness severity and children's psychosocial functioning is unclear. Researchers have alternately found positive correlations between severity and problems (e.g., Hommel et al., 2003; McQuaid et al., 2001), no association between the two (Kashani, König, Shepperd, \& Wilfley, 1988), and results suggesting that children with mild illness have more psychosocial problems than their peers with moderate or severe illness (e.g., Piazza-Waggoner, Adams, Muchant, Wilson, \& Hogan, 2008). Inconsistencies in the measurement of illness severity may underlie these disparate results, but it is also likely that moderators influence the association between illness severity and psychosocial functioning.

\section{Life Stress and Internalizing Problems}

Children living in low-income environments may face a constellation of stressors related to economic strain, exposure to violence, family turmoil, overcrowding, substandard housing, and environmental hazards. Race-based disparities in stress may impose further risk on children and families from minority groups; for instance, there is evidence that minorities experience higher levels of stress than whites (Kessler, Mickelson, \& Williams, 1999) and are more severely affected by stress (Perilla, Norris, \& Lavizzo, 2002). Stressors like these associated with sociodemographic disadvantage often co-occur and thus have been empirically examined in the form of cumulative risk indices that are clearly linked with compromises in children's psychosocial functioning (Gutman, Sameroff, \& Cole, 2003; 
Lengua, 2002) as well as physiological burden (i.e., allostatic load; Evans, Kim, Ting, Tesher \& Shannis, 2007). Poverty Related Stress (PRS) has been empirically associated with childhood psychosocial problems (Wadsworth et al., 2008), and more specifically with anxiety (Wadsworth \& Santiago, 2008). There is also evidence that high PRS can hinder the development of adaptive ways of coping among children (Wadsworth \& Compas, 2002).

\section{Coping with Stressors}

Across a substantial body of literature on children's coping with life stress, children who utilize active coping have been found to enjoy slightly better psychosocial functioning when compared to their peers (Clarke, 2006; Wadsworth \& Santiago, 2008). Benefits of active approaches to coping with asthma have been documented as well (Marsac, Funk, \& Nelson, 2006). However, associations among coping constructs and asthma-related functioning are not clear-cut. For instance, Koinis Mitchell and Murdock (2002) found that active and avoidant coping strategies were significantly correlated with one another and associated with better asthma management and activity participation among urban children with asthma. Similarly, Shreier and Chen (2008) found that primary and secondary coping strategies were significantly correlated with one another and associated with increases in asthma treatment over the course of one year.

There is increasing evidence that the effects of coping are moderated by other factors (Kliewer et al., 2006), such as the controllability and/or severity of the stressor. Specifically, active and primary control coping strategies have been related to better functioning in the context of controllable stressors (Clarke, 2006; Jaser et al., 2007). For uncontrollable stress (Compas, Banez, Malcarne, \& Worsham, 1991; Osowiecki \& Compas, 1998) or high levels of stress (Gonzales, Tein, Sandler, \& Friedman, 2001; Pina et al., 2008), active coping either loses its potency as a resource or functions as a liability for children's well-being (Clarke, 2006). Greene, Murdock, and Koinis Mitchell (2006) found that in a sample of urban, minority children with asthma, both problem-solving coping and avoidant coping were associated with less social withdrawal only among children with low asthma-related stress.

Taken together, these findings paint a blurry picture of what constitutes adaptive coping among children facing life stressors and asthma. This could stem from a poor fit of traditional classifications of child coping to samples of high risk children. In fact, there is evidence that coping constructs may not apply to children who are demographically different than normative samples used to derive them, such as low-income, minority children (Gaylord-Harden, Gipson, Mance, \& Grant, 2008). Patterns and norms of coping may be culture- or setting-specific, so that traditional assessment tools are unequally sensitive across children with diverse backgrounds and experiences. This would explain why the factor structure of dominant coping measures has not been replicated in some studies of ethnic minority and/or highly stressed youth (e.g., Tolan et al., 2002). Inconsistency in this literature may also stem from the dynamic nature of stressors that children living with asthma in urban neighborhoods may face, including a combination of experiences that can be managed (e.g., chronic, low-level problems and symptoms) and experiences that are firmly outside of the child's control (e.g., major life events and asthma attacks). Instead of examining broad classifications of coping behaviors, researchers have called for further studies incorporating fine-grained analysis of narrowly defined aspects of coping, such as problem-solving efficacy, in order to generate more direct implications for intervention development (Blount et al., 2008; McQuaid et al., 2001).

\section{Perceived Problem-Solving Efficacy}

Several explanations have been put forth to explain why the benefits of active coping strategies, such as problem-solving coping, diminish in contexts of high and/or 
uncontrollable stress. One interpretation is that duress causes individuals to problem-solve less competently than usual. Cumulative stress not only increases individuals' vulnerability to experience additional stress but also depletes their resources for coping in the moment (Wadsworth, Raviv, Compas, \& Connor-Smith, 2005) and may compromise the development of effective coping over time (Wadsworth \& Compas, 2002). Furthermore, stress reduces the attentional resources that are required for coping strategies such as problem-solving, which has a relatively high cognitive burden (Matthews \& Wells, 1996). Another explanation is that even the most competent problem-solving does not work when it is beyond the control of the individual to change a stressful situation. In either scenario, an individual with a problem-solving orientation may suffer from feelings of inefficacy or helplessness when trying to utilize problem-solving strategies in high stress contexts, and this may contribute to psychological compromises associated with exposure to stress.

Therefore, perceived problem-solving efficacy is a coping-related construct that has subtle implications for understanding active coping attempts among children in high stress contexts. Coping efficacy in general has been investigated with regard to a range of stressors. It has been identified as a direct predictor and/or mediator in the prediction of internalizing problems among children facing bereavement (Wolchik, Tein, Sandler, \& Ayers, 2006), ecological risk (Prelow, Weaver, \& Swenson, 2006), and interparental conflict (Gerard, Buehler, Franck, \& Anderson, 2005). It has also been found to fully mediate the relationship between coping behaviors and internalizing problems (Sandler, Tein, Mehta, Wolchik \& Ayers, 2000; Mosher \& Prelow, 2007) and to mediate between parenting and internalizing problems (Smith et al., 2006). More specifically, problem-solving efficacy has been linked concurrently and longitudinally with children's higher expectations for the future, which are in turn associated with more positive behavioral adjustment (Dubow, Arnett, Smith \& Ippolito, 2001).

\section{The Current Study}

The current study explored associations among children's asthma-related and life stressors, problem-solving coping efficacy, and anxiety symptoms. Participants included parent-child dyads, most of whom were members of ethnic minority groups, living with pediatric asthma in low-income, urban neighborhoods. Based on previous evidence that the utility of active coping strategies can become attenuated under conditions of high stress, it was hypothesized that problem-solving efficacy would moderate the associations of asthma-related stress and life stress with children's anxiety. It was expected that children's perceptions of high problem-solving efficacy would exacerbate children's vulnerability to stress, such that the highest levels of anxiety would be reported by children experiencing high levels of stress and high problem-solving efficacy.

\section{METHOD}

\section{Participants}

Two families were excluded from the current analyses due to missing data. The final sample included 23 girls and 22 boys, all of whom had an active asthma diagnosis made by a physician. Children were between the ages of 7 and 12 years $(M=9.3, S D=1.2)$. Approximately $85 \%$ of children were members of ethnic minority groups, with $38 \%$ African-American, 38\% Hispanic, 9\% Multiracial, 9\% White, and 6\% not reported. Children's asthma severity ratings were as follows: mild intermittent $(n=23)$, mild persistent $(n=8)$, moderate persistent $(n=13)$, and severe persistent $(n=1)$. Primary caregivers were between the ages of 20 and 65 years $(M=37.9, S D=10.1)$ and were female in all but one case. Additional family characteristics are presented in Table 1. 


\section{Design and Procedures}

Children with asthma and their primary caregivers were recruited from five community health centers in Boston, Massachusetts. Health center staff members generated mailing lists of children whose records indicated an asthma diagnosis and recruitment materials were mailed to their parents at home. Staff members also provided information to eligible families during children's medical appointments. All recruitment materials and assessment measures were made available in English and Spanish. Materials were translated from English into Spanish with forward, backward, and consensus translation procedures. For families who preferred Spanish, all verbal and written correspondences were conducted by native Spanish-speaking research assistants.

Forty-seven families volunteered to participate. Parent-child dyads were interviewed in comfortable laboratory rooms at an urban university located in the recruitment neighborhood. Separate and confidential interviews with primary caregivers and children were approximately 90 minutes long. Thirteen caregiver interviews were conducted in Spanish by bilingual, native Spanish-speaking interviewers. With separate consent, data were also collected from children's teachers and medical charts. Cab vouchers, parking passes, and/or public transportation funds were provided, as well as free child care for siblings of participating children. A thank you gift of $\$ 20$ and small prizes were provided to each participant.

\section{Measures}

Table 2 presents descriptive statistics and internal consistency data for primary study variables.

Demographic information-Family characteristics were reported by the parent. An open-ended question was asked regarding the racial/ethnic group(s) with which each parent and child primarily identified, and these labels were categorized under the umbrella terms utilized by the 2004 U.S. Census Bureau. Parental education was coded on a scale ranging from 1 (Did not finish high school) to 7 (Master's degree or higher). Occupational prestige scores were determined for employed parents based on the National Opinion Research Center (NORC) coding system (Nakao and Treas, 1990). NORC codes can range from 17 to 86, with higher scores indicating more prestige (e.g., Sales Associate in a Clothing Store: 30.22; Preschool Teacher: 54.93). To assess perceived socioeconomic status, participants completed the Scale of Subjective Status (Adler, Epel, Castellanzzo, \& Ickovics, 2000) in which they placed themselves on a ten-rung ladder with higher rungs reflecting greater social status.

Asthma-Related Stress-Three indicators of asthma-related stress were utilized: Asthma severity ratings, parent-reported asthma symptoms, and children's perceptions of asthma symptom burden.

Children's asthma severity ratings ( $1=$ mild intermittent to $4=$ severe persistent $)$ were made by health care providers and recorded from medical charts for 32 children in this dataset. For 11 children, medical chart data were not available and asthma severity ratings were coded on the basis of parent-reported symptoms and medications following the 2002 National Asthma Education and Prevention Program guidelines (National Institutes of Health, 2002), which were the convention at the time of data collection. For two children, neither medical chart nor medication data were available and parent-reported severity ratings were utilized.

Parents were asked how frequently in the past month their child had experienced four primary asthma symptoms (i.e., "wheezing," "trouble catching her/his breath," "pain or 
tightness in her/his chest," and "uncontrollable coughing"). First they responded on a 6point scale ranging from 0 (not at all) to 5 (every day). Next, they reported whether the symptom typically occurred during the day and/or at night. Symptom frequency scores were created for each of the four symptoms, in which a score of 0 indicates that the child did not experience the symptom, a score of 1 indicates that the symptom occurred less than once a week, during the day or at night, a score of 2 indicates that the symptom occurred less than once a week, during the day and at night. Scores ranged up to 10, which indicates that the symptom occurred every day, during the day and at night. The total asthma symptom frequency score was calculated by summing these scores for each of the four symptoms. Internal consistency for this measure with this sample of children was satisfactory (Chronbach's $\mathrm{a}=.71$ ).

The symptoms subscale of the Pediatric Asthma Quality of Life Questionnaire (PAQLQ; Juniper, Guyatt, Feeny, \& Ferrie, 1996) was utilized as a measure of children's perceived symptom burden. The PAQLQ assesses three domains of functional impairment due to asthma: symptoms (10 items), emotional functioning ( 8 items), and activity limitations (5 items). The symptoms subscale was utilized in this study with a one-year frame of reference, including items such as "How much did coughing bother you in the past year?" and "How often did you feel out of breath during the past year?" Children responded on a 7-point scale ranging from 1 (none of the time) to 7 (all of the time) with higher responses indicating greater perceived asthma symptom burden. Good internal consistency has been reported for the total PAQLQ (Juniper et al., 1996; Everhart, Fiese \& Smyth, 2008). Cronbach's a for the symptoms subscale in the current sample was .86.

In order to create a composite variable of equally weighted asthma severity ratings, parentreported asthma symptoms, and children's perceptions of asthma symptom burden, these variables were $\mathrm{z}$-scored and summed.

Child's Life Stress-The 29-item Life Events Scale (D'Imperio, Dubow \& Ippolito, 2000) was administered to children, who indicated whether each experience had happened to them in the past year $(0=$ no, $1=y e s)$. Stressors, including major life events and exposure to community disadvantage and violence, were selected for this measure by its authors on the basis of being empirically linked to children's adjustment problems and outside of children's control. In the current study, one additional catch-all item ("Has anything else happened that has been upsetting to you and your family?") was included in the total score. Approximately one quarter of respondents endorsed a stressor in this category, with descriptions ranging from being teased at school to extended family and/or community discord. D'Imperio et al. (2000) reported an internal consistency of .81 in a demographically similar sample of early adolescents. Cronbach's a for the Life Events Scale in the current sample was .80.

Children's Perceived Problem-Solving Efficacy-Children responded to six items concerning their use of problem-solving skills (Schmidt \& Dubow, 1998) using a 5-point scale ( $1=$ never, $5=$ =always). Sample items include "When you have a problem, you think of different ways to solve it" and "When you have a problem you can't change, you still come up with ways to help yourself feel better." Measures of internal consistency in previous samples of fifth through eighth grade students ranged from .62 to .78 (Schmidt \& Dubow, 1998; Dubow, Arnett, Smith \& Ippolito, 2001). This measure has been positively correlated with self-reported coping strategies of support seeking and self-reliance and negatively correlated with internalizing symptoms in other samples (Dubow et al., 2001). Cronbach's a for this measure in the current sample was .72 .

Child's Anxiety-The Self-Report Scale (SRS) of the Behavioral Assessment System for Children (BASC) was administered to children, involving a series of statements to which 
they responded "true" or "false" (Reynolds and Kamphaus, 1998). The Anxiety subscale consists of 17 items assessing feelings of nervousness, worry, and fear, and the tendency to be overwhelmed by problems. Sample items are "I am nervous" and "I worry when I go to bed at night". T-scores above 64 reflect clinically significant levels of anxiety and the clear presence of psychological distress. At-risk scores between 60 and 64 indicate acute or chronic anxiety. In the BASC normative sample containing children from diverse ethnic and socioeconomic backgrounds, this subscale had an internal consistency of .87 (Reynolds \& Kamphaus, 1998).

\section{Preliminary Analyses}

A correlation matrix of primary study variables is presented in Table 3. No significant correlations emerged between demographic and primary study variables. T-tests revealed no significant gender differences in primary study variables.

\section{RESULTS}

Hierarchical regression analyses were conducted to test hypotheses. Predictor variables were centered at their means. Separate regressions were conducted for asthma-related stress and life stress in association with children's anxiety. In the first step of each regression model, asthma-related stress or life stress was entered, in the second step, problem-solving efficacy was entered, and in the third step, the interaction term (asthma-related stress/life stress $\times$ problem-solving efficacy) was entered in order to test moderation. To interpret significant interactions, simple slopes analyses were conducted by regressing child anxiety on the relevant stress variable at low (1 $S D$ below the mean), average, and high (1 $S D$ above the mean) values of problem solving efficacy (Aiken \& West, 1991).

\section{Asthma-Related Stress, Problem-Solving Efficacy and Anxiety}

Results for asthma-related stress are presented in Table 4. In step one, higher asthma-related stress was significantly associated with greater anxiety. In step two, problem-solving efficacy did not account for significant variance in the outcome. In step three, the interaction of asthma-related stress $\times$ problem-solving efficacy was significant.

Decomposing this significant interaction with simple slope analyses revealed that asthmarelated stress was significantly and positively associated with anxiety for children with high levels of problem-solving efficacy ( $1 S D$ above the mean; $B=2.03, S E B=0.71, \beta=.57, p$ $=.007)$, but not a significant predictor for children with average $(B=0.95, S E B=0.50, \beta$ $=.27, p=.07$ ) or low levels ( $S D$ below the mean; $B=-0.12, S E B=0.75, \beta=-.04, p=$. $87)$.

\section{Life Stress, Problem-Solving Efficacy and Anxiety}

Results for life stress are presented in Table 4. In step one, higher life stress was significantly associated with greater anxiety. In step two, problem-solving efficacy did not account for significant variance. In step three, the interaction of life stress $\times$ problem-solving efficacy was significant.

Decomposing this significant interaction with simple slope analyses revealed that life stress was significantly and positively associated with anxiety for children with high levels of problem-solving efficacy ( $1 S D$ above the mean; $B=4.04, S E B=1.16, \beta=.58, p=.001$ ), but not a significant predictor for children with average $(B=1.48, S E B=0.98, \beta=.21, p$ $=.14$ ) or low levels ( $1 S D$ below the mean; $B=-1.08, S E B=1.56, \beta=-.16, p=.49)$. 


\section{DISCUSSION}

In this sample of low-income children living in urban neighborhoods, the nature of associations between stress and anxiety differed as a function of children's problem-solving efficacy. Asthma-related stress and life stress were positively associated with anxiety only for children who had the highest levels of problem-solving efficacy. In other words, positive expectations about the ability to solve problems functioned as a liability for highly stressed children. Stress was not significantly associated with anxiety among children who were characterized by average or low levels of problem-solving efficacy.

Previous literature has demonstrated that when stressors are uncontrollable and/or relatively high in intensity, the use of active coping strategies such as problem-solving may not be most adaptive. The current findings indicate that perceptions of problem-solving efficacy operate similarly. It is possible that anxiety is generated by the disconnect between high efficacy expectations and a compromised ability to bring about favorable outcomes through problem-solving. The Helplessness-Hopelessness perspective of anxiety and depression (Alloy, 1991; Alloy, Kelly, Mineka \& Clements, 1990) may shed light on this phenomenon. In this perspective, when an individual tries unsuccessfully to achieve control over stressful experiences, a sense of helplessness ensues. As long as the individual is uncertain about this helplessness, anxiety will be experienced and efforts will be made to gain control over stressors. If the certainty of helplessness evolves into hopelessness, mastery attempts may cease as depressive symptoms occur.

Thus, children with high problem-solving efficacy who experience a high volume of stressors with a range of controllability may remain in a state of uncertain helplessness and anxiety. Although in this study the checklist of life stressors included events considered to be outside children's control, it can be assumed that these events serve as proxies for a range of day-to-day situations of varying controllability with which children must cope. Similarly, children's control over asthma-related stress tends to fluctuate in response to asthma exacerbations. Children's generally positive sense of problem-solving efficacy may be fueled by variable success in attempts to gain control over stressors and accompanied by a tendency toward arousal and anxiety.

In this study, asthma-related stress and life stress were directly and interactively (with problem-solving efficacy) associated with children's anxiety in a parallel pattern. The children in this sample, who are from low socioeconomic status, minority, and urban backgrounds, represent the highest risk group for experiencing asthma and its associated stressors. By virtue of their sociodemographic characteristics, they also face heightened risk for a range of life stressors. However, in previous research these stressors have not been examined simultaneously. The current findings suggest that in the future a cumulative risk model may be appropriate for assessing links between problem-solving efficacy and psychological adjustment among children coping with asthma in urban settings.

It should be noted that the mean level of children's self-reported problem-solving efficacy was higher in the current sample of first through fifth graders (25.07) than in a demographically similar sample of sixth, seventh and eighth graders (21.63; Dubow et al., 2001). It is unclear whether children's estimates of their problem-solving efficacy may have been positively biased in this study. Additional studies are necessary to establish normative levels of problem-solving efficacy across developmental periods and levels of stress exposure. 


\section{Clinical Implications}

Although problem-solving coping behaviors can be promising behavioral targets for child clinical interventions (e.g., Cunningham, Brandon \& Frydenberg, 2002), it is clear that effective coping interventions must take a child's context into account (Clarke, 2006). The current findings reinforce that it is crucial for interventionists to teach a range of coping behaviors along with strategies for assessing when they will be most helpful. It would be an overstatement to conclude that children facing many stressors should not be taught active coping or problem-solving strategies. However, appraisal processes must be included in this training. For instance, the problem-solving process should include identifying the specific problem, evaluating its controllability, generating a list of positive and negative behaviors or cognitions to solve the problem, identifying the most adaptive strategies, and systemically trying strategies until they find one that works well. When children are equipped with competence in a variety of coping strategies and can choose problem-solving approaches in response to problems that can actually be solved, the accuracy of their perceptions of problem-solving efficacy as well as their psychological adjustment is likely to be optimized.

Empirically evaluated intervention programs should examine the utility of asthma-specific problem-solving for children with asthma. Teaching children specific asthma management strategies that they can master (e.g., avoiding asthma triggers, proper medication use) could help them to reduce the anxiety caused by their illness.

Children's strengths should be capitalized upon in coping interventions for children facing a combination of illness and life stress. Results of previous studies raise intriguing questions about the utility versus liability of exposure to stressors as training ground for the development of effective coping as well as perceptions of coping efficacy. Although severe and/or sustained stressors may compromise children's abilities to problem-solve adaptively (Wadsworth \& Compas, 2002), it also has been found that children with chronic illness are more effective copers than their healthy peers (Hampel, Rudolph, Stachow, Laß-Lentzsch, $\&$ Petermann, 2005) and that children with mild illnesses have less adaptive coping than children with more severe illnesses (Piazza-Waggoner et al., 2008). Thus, it should be acknowledged that children facing illness-related stressors may actually build strengths through practice in coping.

\section{Limitations of this study}

The current study addresses an understudied population and a construct, problem-solving efficacy, which has received little attention in the literature thus far. Findings should be interpreted with caution, however. Statistical power of this study was limited by a small sample size. Families in this study were drawn from five community health centers that collectively serve a large number of children with asthma. Those that participated may not be fully representative of families served in urban community health centers, as they may be characterized by fewer asthma-related and/or life stressors that would pose a barrier to participation. The mean asthma severity level in this sample was in the mild/intermittent to mild/persistent range and thus, results of this study may not reflect the experiences of children with the most severe asthma-related stress. Further research is needed to examine asthma control as a covariate of children's coping and internalizing problems. Temporal or causal associations among variables cannot be determined in this dataset. Although the use of multiple reporters is a strength of the study, common method variance may have affected some findings. A measure of dispositional problem-solving efficacy was utilized in this study; future research should address situation-specific coping strategies and efficacy. There are benefits to focusing on narrow aspects of coping such as problem-solving efficacy, but it would also be helpful to understand it within a broader context or profile of coping (Gonzales et al., 2001). 


\section{Future Research}

Future research should explore more complex interactions in the development and implications of problem-solving efficacy. For instance, there is evidence that family factors can moderate or mediate children's biological and psychosocial responses to cumulative stress across developmental periods and social contexts (e.g., Loukas, Prelow, Suizzo, \& Allua, 2008; Trentacosta et al., 2008). Empirical results have been inconsistent regarding differences in stress and coping across gender and ethnicity (e.g., Amirkhan \& Auyeung, 2007; Jose \& Kilburg, 2007), suggesting the existence of unexplored moderating variables in these relationships. Intriguing age-related trends in active coping have been identified, including a general trend toward the increasing use of problem-solving coping with age (e.g., Amirkhan \& Augeung, 2007) and a more robust association between active coping and internalizing problems among adolescents when compared to pre-adolescents (Clarke, 2006). Further research exploring developmental trajectories of coping with consideration of sociodemographic, social context, and intrapsychic factors (e.g., attributions of stressor controllability; coping efficacy) would be useful in the creation of effective coping interventions. Research on children's coping should continue to expand beyond the prediction of psychopathology to explore the conditions under which it can promote specific competencies and prosocial engagement (e.g., Reschly, Huebner, Appleton, \& Antaramian, 2008).

\section{Acknowledgments}

Funding for this study was provided by a grant awarded to the first author by the National Institutes of Health (MH63165). Appreciation is expressed to Jennifer Bender Berz, Michael Rollock, Ana Diaz, and Yudy Muneton for their assistance in the conceptualization and implementation of the study.

\section{References}

Adler NE, Epel ES, Castellazzo G, Ickovics JR. Relationship of subjective and objective social status with psychological and physiological functioning: Preliminary data in healthy, white women. Health Psychology. 2000; 19:586-592. [PubMed: 11129362]

Aiken, L.; West, S. Multiple regression: Testing and interpreting interactions. Thousand Oaks, CA: Sage Publications, Inc; 1991.

Alati R, O’Callaghan M, Najman JM, Williams GM, Bor W, Lawlor DA. Asthma and internalizing behavior problems in adolescence: A longitudinal study. Psychosomatic Medicine. 2005; 67:462470. [PubMed: 15911911]

Alloy LB. Depression and anxiety: Disorders of emotion or cognition? Psychological Inquiry. 1991; 2:72-74.

Alloy, LB.; Kelly, KA.; Mineka, S.; Clements, CM. Comorbidity of anxiety and depressive disorders: A helplessness-hopelessness perspective. In: Maser, JD.; Cloninger, CR.; Maser, JD.; Cloninger, CR., editors. Comorbidity of mood and anxiety disorders. Washington, DC US: American Psychiatric Association; 1990. p. 499-543.

American Lung Association, Epidemiology and Statistics Unit, Research and Program Services. Trends in asthma morbidity and mortality. 2007. Retrieved September 15 2008, from http:// www.lungusa.org/atf/cf/\%7B7a8d42c2-fcca-4604-8ade7f5d5e762256\%7D/ ASTHMA_TREND_NOV2007.PDF

Amirkhan J, Auyeung B. Coping with stress across the lifespan: Absolute vs. relative changes in strategy. Journal of Applied Developmental Psychology. 2007; 28:298-317.

Blount RL, Simons LE, Devine KA, Jaaniste T, Cohen LL, Chambers CT, et al. Evidence-based assessment of coping and stress in pediatric psychology. Journal of Pediatric Psychology. 2008; 33:1021-1045. [PubMed: 17938147]

Castro M, Schechtman KB, Halstead J, Bloomberg G. Risk factors for asthma morbidity and mortality in a large metropolitan city. The Journal of Asthma: Official Journal of the Association for the Care of Asthma. 2001; 38:625-635. [PubMed: 11758891] 
Centers for Disease Control and Prevention. Asthma's impact on children and adolescents. 2006. Retrieved May 13 2008, http://www.cdc.gov/asthma/children.htm2006

Clarke AT. Coping with interpersonal stress and psychosocial health among children and adolescents: A meta-analysis. Journal of Youth and Adolescence. 2006; 35:11-24.

Compas BE, Banez GA, Malcarne V, Worsham N. Perceived control and coping with stress: A developmental perspective. Journal of Social Issues. 1991; 47:23-34.

Cunningham EG, Brandon CM, Frydenberg E. Enhancing coping resources in early adolescence through a school-based program teaching optimistic thinking skills. Anxiety, Stress \& Coping: An International Journal. 2002; 15:369-381.

D'Imperio RL, Dubow EF, Ippolito MF. Resilient and stress-affected adolescents in an urban setting. Journal of Clinical Child Psychology. 2000; 29:129-142. [PubMed: 10693039]

Dubow EF, Arnett M, Smith K, Ippolito MF. Predictors of future expectations of inner-city children: A 9-month prospective study. The Journal of Early Adolescence. 2001; 21:5-28.

Dubow EF, Schmidt D, McBride J, Edwards S. Teaching children to cope with stressful experiences: Initial implementation and evaluation of a primary prevention program. Journal of Clinical Child Psychology. 1993; 22:428-440.

Evans GW, Kim P, Ting AH, Tesher HB, Shannis D. Cumulative risk, maternal responsiveness, and allostatic load among young adolescents. Developmental Psychology. 2007; 43:341-351. [PubMed: 17352543]

Everhart RS, Fiese BH, Smyth JM. A cumulative risk model predicting caregiver quality of life in pediatric asthma. Journal of Pediatric Psychology. 2008; 33:809-818. [PubMed: 18356183]

Gaylord-Harden NK, Gipson P, Mance G, Grant KE. Coping patterns of african american adolescents: A confirmatory factor analysis and cluster analysis of the children's coping strategies checklist. Psychological Assessment. 2008; 20:10-22. [PubMed: 18315395]

Gerard JM, Buehler C, Franck K, Anderson O. In the eyes of the beholder: Cognitive appraisals as mediators of the association between interparental conflict and youth maladjustment. Journal of Family Psychology. 2005; 19:376-384. [PubMed: 16221018]

Gonzales NA, Tein J, Sandler IN, Friedman RJ. On the limits of coping: Interaction between stress and coping for inner-city adolescents. Journal of Adolescent Research. 2001; 16:372-395.

Goodwin RD, Messineo K, Bregante A, Hoven CW, Kairam R. Prevalence of probable mental disorders among pediatric asthma patients in an inner-city clinic. Journal of Asthma. 2005; 42:643-647. [PubMed: 16266954]

Goodwin RD, Pine DS, Hoven CW. Asthma and panic attacks among youth in the community. Journal of Asthma. 2003; 40:139-145. [PubMed: 12765315]

Greene C, Murdock KK, Mitchell DK. Coping with illness-related stress among urban children with asthma. Children's Health Care. 2006; 35:297-320.

Gutman LM, Sameroff AJ, Cole R. Academic growth curve trajectoiries from 1st grade to 12th grade: Effects of multiple social risk factors and preschool child factors. Developmental Psychology. 2003; 39:777-790. [PubMed: 12859129]

Hampel P, Rudolph H, Stachow R, Laß-Lentzsch A, Petermann F. Coping among children and adolescents with chronic illness. Anxiety, Stress \& Coping: An International Journal. 2005; 18:145-155.

Hommel KA, Chaney JM, Wagner JL, White MM, Hoff AL, Mullins LL. Anxiety and depression in older adolescents with long-standing asthma: The role of illness uncertainty. Children's Health Care. 2003; 32:51-63.

Jaser SS, Champion JE, Reeslund KL, Keller G, Merchant MJ, Benson M, et al. Cross-situational coping with peer and family stressors in adolescent offspring of depressed parents. Journal of Adolescence. 2007; 30:917-932. [PubMed: 17241658]

Jose PE, Kilburg DF III. Stress and coping in Japanese children and adolescents. Anxiety, Stress \& Coping: An International Journal. 2007; 20:283-298.

Josie KL, Greenley RN, Drotar D. Cumulative risk and asthma outcomes in inner-city africanamerican youth. Journal of Asthma. 2007; 44:535-541. [PubMed: 17885856] 
Juniper EF, Guyatt GH, Feeny DH, Ferrie PJ. Measuring quality of life in children with asthma. Quality of Life Research: An International Journal of Quality of Life Aspects of Treatment, Care \& Rehabilitation. 1996; 5:35-46.

Kashani JH, König P, Shepperd JA, Wilfley DE. Psychopathology and self-concept in asthmatic children. Journal of Pediatric Psychology. 1988; 13:509-520. [PubMed: 3216273]

Katon WJ, Richardson L, Russo J, Lozano P, McCauley E. Quality of mental health care for youth with asthma and comorbid anxiety and depression. Medical Care. 2006; 44:1064-1072. [PubMed: 17122709]

Kessler RC, Mickelson KD, Williams DR. The prevalence, distribution, and mental health correlates of percieved discrimination in the united states. Journal of Health and Social Behavior. 1999; 40:208-230. [PubMed: 10513145]

Kliewer W, Parrish KA, Taylor KW, Jackson K, Walker JM, Shivy VA. Socialization of coping with community violence: Influences of caregiver coaching, modeling, and family context. Child Development. 2006; 77:605-623. [PubMed: 16686791]

Koinis Mitchell D, Murdock KK. Self-competence and coping in urban children with asthma. Children's Health Care. 2002; 31:273-293.

Koinis Mitchell D, Murdock KK. Identifying risk and resource factors in children with asthma from urban settings: The context-health-development model. Journal of Asthma. 2005; 42:425-436. [PubMed: 16293537]

Lengua LJ. The contribution of emotionality and self-regulation to the understanding of children's response to multiple risk. Child Development. 2002; 73:144-161. [PubMed: 14717249]

Loukas A, Prelow HM, Suizzo M, Allua S. Mothering and peer associations mediate cumulative risk effects for latino youth. Journal of Marriage and Family. 2008; 70:76-85.

Marsac ML, Funk JB, Nelson L. Coping styles, psychological functioning and quality of life in children with asthma. Child: Care, Health and Development. 2007; 33:360-367.

Matthews, G.; Wells, A. Attentional processes, dysfunctional coping, and clinical intervention. In: Zeidner, M.; Endler, NS.; Zeidner, M.; Endler, NS., editors. Handbook of coping: Theory, research, applications. Oxford England: John Wiley \& Sons; 1996. p. 573-601.

McQuaid EL, Kopel SJ, Nassau JH. Behavioral adjustment in children with asthma: A meta-analysis. Journal of Developmental \& Behavioral Pediatrics. 2001; 22:430-439. [PubMed: 11773808]

Moonie SA, Sterling DA, Figgs L, Castro M. Asthma status and severity affects missed school days. The Journal of School Health. 2006; 76:18-24. [PubMed: 16457681]

Mosher CE, Prelow HM. Active and avoidant coping and coping efficacy as mediators of the relation of maternal involvement to depressive symptoms among urban adolescents. Journal of Child and Family Studies. 2007; 16:876-887.

National Institutes of Health, National Heart, Lung and Blood Institute, National Asthma Education and Prevention Program. Clinical Practice Guidelines. Bethesda, MD: NIH; 2002. Expert Panel Report:Guidelines for the Diagnosis and Management of Asthma-Update on Selected Topics 2002. NIH Publication No. 02-5075

Newacheck PW, Halfon N. Prevalence, impact, and trends in childhood disability due to asthma. Archives of Pediatrics \& Adolescent Medicine. 2000; 154:287-293. [PubMed: 10710030]

Noeker M, Petermann F. Children's and adolescents' perception of their asthma bronchiale. Child: Care, Health and Development. 1998; 24:21-30.

Osowiecki D, Compas BE. Psychological adjustment to cancer: Control beliefs and coping in adult cancer patients. Cognitive Therapy and Research. 1998; 22:483-499.

Nakao, K.; Treas, J. Computing 1989 Occupational Prestige Scores. Chicago: National Opinion Research Center; 1990.

Padur JS, Rapoff MA, Houston BK, Barnard M. Psychosocial adjustment and the role of functional status for children with asthma. Journal of Asthma. 1995; 32:345-353. [PubMed: 7559275]

Perilla JL, Norris FH, Lavizzo EA. Ethnicity, culture, and disaster response: Identifying and explaining ethnic differences in PTSD six months after hurricane andrew. Journal of Social \& Clinical Psychology. 2002; 21:20-45. 
Piazza-Waggoner C, Adams CD, Muchant D, Wilson NW, Hogan MB. Coping and adjustment in children with primary immunodeficiency disorders and kidney diseases: The role of illness severity. Children's Health Care. 2008; 37:210-224.

Pina AA, Villalta IK, Ortiz CD, Gottschall AC, Costa NM, Weems CF. Social support, discrimination, and coping as predictors of posttraumatic stress reactions in youth survivors of hurricane katrina. Journal of Clinical Child and Adolescent Psychology. 2008; 37:564-574. [PubMed: 18645747]

Prelow HM, Weaver SR, Swenson RR. Competence, self-esteem, and coping efficacy as mediators of ecological risk and depressive symptoms in urban african american and european american youth. Journal of Youth and Adolescence. 2006; 35:507-517.

Reschly AL, Huebner ES, Appleton JJ, Antaramian S. Engagement as flourishing: The contribution of positive emotions and coping to adolescents' engagement at school and with learning. Psychology in the Schools. 2008; 45:419-431.

Reynolds, CR.; Kamphaus, RW. BASC: Behavioral Assessment System for Children Manual. Circle Pines, NJ: American Guidance Services, Inc; 1998.

Röder I, Kroonenberg PM, Boekaerts M. Psychosocial functioning and stress-processing of children with asthma in the school context: Differences and similarities with children without asthma. Journal of Asthma. 2003; 40:777-787. [PubMed: 14626334]

Sandler IN, Tein J, Mehta P, Wolchik S, Ayers T. Coping efficacy and psychological problems of children of divorce. Child Development. 2000; 71:1099-1118. [PubMed: 11016569]

Schmidt, D.; Dubow, EF. Unpublished raw data. 1998. A six-month and one-year follow-up study of the effects of a primary prevention program for fourth graders.

Schreier HMC, Chen E. Prospective associations between coping and health among youth with asthma. Journal of Consulting and Clinical Psychology. 2008; 76:790-798. [PubMed: 18837596]

Smith CL, Eisenberg N, Spinrad TL, Chassin L, Morris AS, Kupfer A, et al. Children's coping strategies and coping efficacy: Relations to parent socialization, child adjustment, and familial alcoholism. Development and Psychopathology. 2006; 18:445-469. [PubMed: 16600063]

Taras H, Potts-Detema W. Childhood asthma and student performance at school. Journal of School Health. 2005; 75:296-312. [PubMed: 16179080]

Tolan PH, Gorman-Smith D, Henry D, Chung K, Hunt M. The relation of patterns of coping of innercity youth to psychopathology symptoms. Journal of Research on Adolescence. 2002; 12:423-449.

Trentacosta CJ, Hyde LW, Shaw DS, Dishion TJ, Gardner F, Wilson M. The relations among cumulative risk, parenting, and behavior problems during early childhood. Journal of Child Psychology and Psychiatry. 2008; 49:1211-1219. [PubMed: 18665880]

Vila G, Nollet-Clemençon C, de Blic J, Mouren-Siméoni M, Scheinmann P. Prevalence of DSM IV anxiety and affective disorders in a pediatric population of asthmatic children and adolescents. Journal of Affective Disorders. 2000; 58:223-231. [PubMed: 10802131]

Wadsworth ME, Compas BE. Coping with family conflict and economic strain: The adolescent perspective. Journal of Research on Adolescence. 2002; 12:243-274.

Wadsworth ME, Raviv T, Compas BE, Connor-Smith JK. Parent and adolescent responses to povertyrelated stress: Tests of mediated and moderated coping models. Journal of Child and Family Studies. 2005; 14:283-298.

Wadsworth ME, Raviv T, Reinhard C, Wolff B, Santiago CD, Einhorn L. An indirect effects model of the association between poverty and child functioning: The role of children's poverty-related stress. Journal of Loss \& Trauma. 2008; 13:156-185.

Wadsworth ME, Santiago CD. Risk and resiliency processes in ethnically diverse families in poverty. Journal of Family Psychology. 2008; 22:399-410. [PubMed: 18540768]

Wolchik SA, Tein J, Sandler IN, Ayers TS. Stressors, quality of the child-caregiver relationship, and children's mental health problems after parental death: The mediating role of self-system beliefs. Journal of Abnormal Child Psychology. 2006; 34:221-238. [PubMed: 16502140] 
Table 1

Demographic Characteristics of Participating Families $(\mathrm{N}=45)$

\begin{tabular}{|c|c|c|c|}
\hline Variable & $\%$ of sample & $M(S D)$ & Range \\
\hline \multirow[t]{6}{*}{ Parent's education level } & \multicolumn{3}{|c|}{$22.2 \%$ Did not finish high school } \\
\hline & \multicolumn{3}{|c|}{$35.5 \%$ High school graduate/GED ${ }^{a}$} \\
\hline & \multicolumn{3}{|c|}{$15.6 \%$ Vocational training } \\
\hline & \multicolumn{3}{|c|}{$17.8 \%$ Associates degree equivalent } \\
\hline & \multicolumn{3}{|c|}{$8.9 \%$ College graduate } \\
\hline & \multicolumn{3}{|c|}{$0 \%$ Postgraduate degree } \\
\hline \multirow[t]{3}{*}{ Parent's occupational status } & \multicolumn{3}{|c|}{$55.6 \%$ Not employed } \\
\hline & \multicolumn{3}{|c|}{$15.6 \%$ Part-time } \\
\hline & \multicolumn{3}{|c|}{$28.9 \%$ Full-time } \\
\hline Parent's occupational prestige & & $41.03(11.32)$ & $23.28-64.08$ \\
\hline Parent's subjective SES $b$ & & $5.07(2.36)$ & $1-10$ \\
\hline Family's monthly income & & $\$ 1,485(\$ 930.60)$ & $\$ 389-\$ 4,500$ \\
\hline \multirow[t]{2}{*}{ Child's school lunch subsidy } & \multicolumn{3}{|c|}{$79.5 \%$ Free lunch } \\
\hline & \multicolumn{3}{|c|}{$6.8 \%$ Reduced price lunch } \\
\hline
\end{tabular}


Table 2

Descriptive Data for Study Variables $(\mathrm{N}=45)$

\begin{tabular}{|c|c|c|c|}
\hline Variable & $M(S D)$ & Possible Range & Range in Sample \\
\hline \multicolumn{4}{|c|}{ Asthma-related stress component variables } \\
\hline Asthma severity & $1.82(.94)$ & $1-4$ & $1-4$ \\
\hline Parent-reported asthma symptoms & $11.24(7.98)$ & $0-30$ & $0-30$ \\
\hline Child-reported symptom burden & $38.51(13.62)$ & $10-70$ & $11-61$ \\
\hline \multicolumn{4}{|l|}{ Predictor variables } \\
\hline Asthma-related stress ${ }^{a}$ & $0.00(1.95)$ & -- & $-3.72-3.68$ \\
\hline Life stress & $10.22(5.53)$ & $0-30$ & $0-26$ \\
\hline Problem-solving efficacy & $25.07(4.38)$ & $6-30$ & $14-30$ \\
\hline \multicolumn{4}{|l|}{ Outcome variable } \\
\hline Anxiety $b$ & $53.36(6.93)$ & $1-100$ & $34-66$ \\
\hline
\end{tabular}




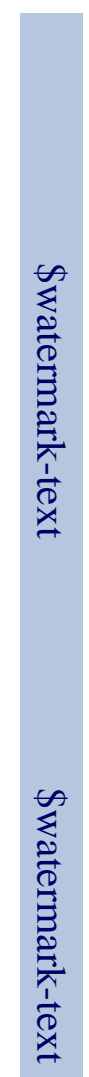

ํㅗㅇ

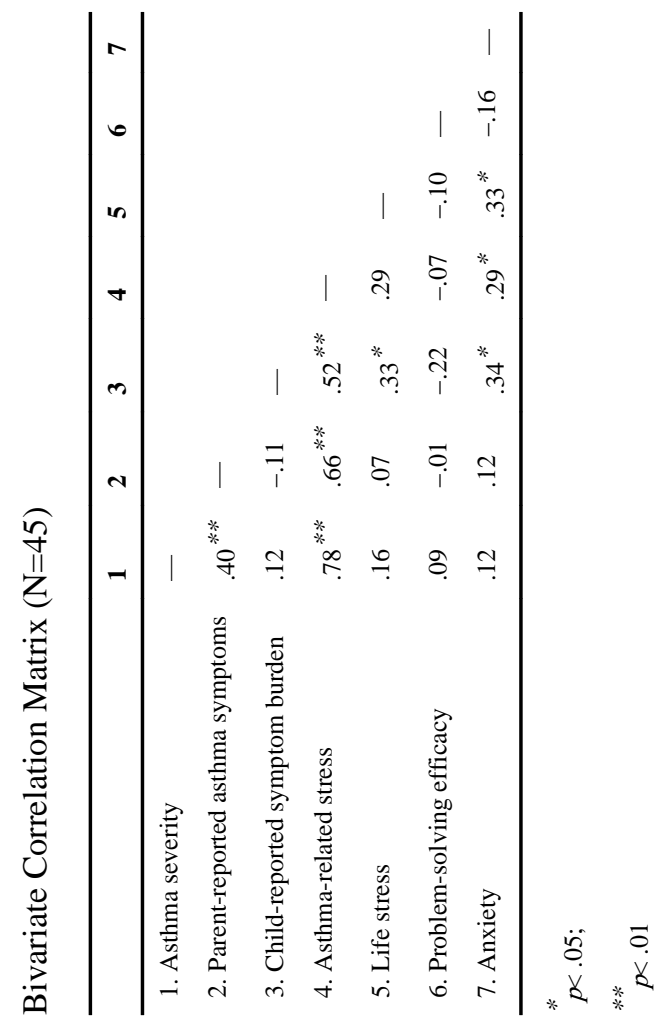

Anxiety Stress Coping. Author manuscript; available in PMC 2012 November 04. 
Table 4

Hierarchical Multiple Regression Analyses predicting Children's Anxiety

\begin{tabular}{|c|c|c|c|c|}
\hline Variable & $\Delta R^{2}$ & $\boldsymbol{B}$ & $S E B$ & $\beta$ \\
\hline Step 1 & $.09^{*}$ & & & \\
\hline Asthma-related stress & & 1.04 & 0.51 & $.29^{*}$ \\
\hline Step 2 & .02 & & & \\
\hline Asthma-related stress & & 1.01 & 0.52 & .29 \\
\hline Problem-solving efficacy & & -0.97 & 1.01 & -.14 \\
\hline Step 3 & $.08^{*}$ & & & \\
\hline Asthma-related stress & & 0.95 & 0.50 & .27 \\
\hline Problem-solving efficacy & & -1.17 & 0.98 & -.17 \\
\hline Asthma-related stress $\times$ problem-solving efficacy & & 1.07 & 0.53 & $.29^{*}$ \\
\hline Step 1 & $.11^{*}$ & & & \\
\hline Life stress & & 2.31 & 0.10 & $.33^{*}$ \\
\hline Step 2 & .02 & & & \\
\hline Life stress & & 2.23 & 1.00 & $.32^{*}$ \\
\hline Problem-solving efficacy & & -0.89 & 1.00 & -.13 \\
\hline Step 3 & $.13^{* * *}$ & & & \\
\hline Life stress & & 1.48 & 0.98 & .21 \\
\hline Problem-solving efficacy & & -1.02 & 0.94 & -.15 \\
\hline Life stress $\times$ problem-solving efficacy & & 2.56 & 0.96 & $.37^{* *}$ \\
\hline \multicolumn{5}{|l|}{$p<.05$} \\
\hline $\begin{array}{l}* * \\
\quad p<.01\end{array}$ & & & & \\
\hline
\end{tabular}

